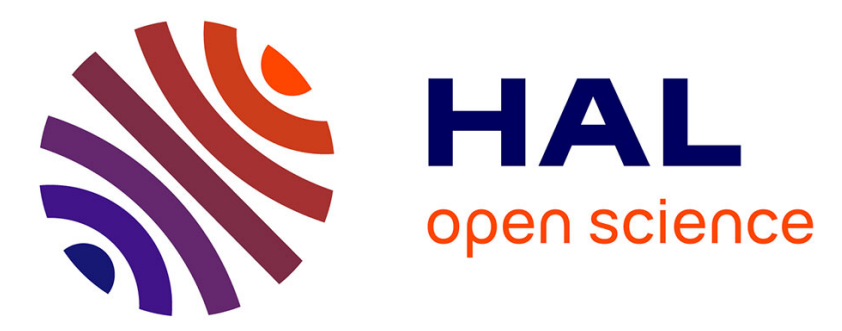

\title{
Multi-arm, multi-stage randomised controlled trials for evaluating therapeutic HIV cure interventions
}

Cecilia Moore, Wolfgang Stohr, Laura Richert, Jean-Daniel Lelievre, Angela Crook, Giuseppe Pantaleo, Felipe Garcia, Stefano Vella, Yves Levy, Rodolphe Thiébaut, et al.

\section{To cite this version:}

Cecilia Moore, Wolfgang Stohr, Laura Richert, Jean-Daniel Lelievre, Angela Crook, et al.. Multiarm, multi-stage randomised controlled trials for evaluating therapeutic HIV cure interventions. The Lancet HIV, 2019, 6 (5), pp.e334-e340. 10.1016/s2352-3018(19)30082-7 . hal-02426904v2

\section{HAL Id: hal-02426904 https://hal.science/hal-02426904v2}

Submitted on 5 Mar 2021

HAL is a multi-disciplinary open access archive for the deposit and dissemination of scientific research documents, whether they are published or not. The documents may come from teaching and research institutions in France or abroad, or from public or private research centers.
L'archive ouverte pluridisciplinaire HAL, est destinée au dépôt et à la diffusion de documents scientifiques de niveau recherche, publiés ou non, émanant des établissements d'enseignement et de recherche français ou étrangers, des laboratoires publics ou privés. 
Title: Multi-arm multi-stage randomised controlled trials for evaluating therapeutic HIV cure interventions

Authors: Cecilia L Moore, $\mathrm{PhD}^{1}$, Wolfgang Stöhr, $\mathrm{PhD}^{1}$, Angela M Crook, $\mathrm{PhD}^{1}$, Laura Richert, $\mathrm{PhD}^{2,3,4}$, Jean-Daniel Leliévre, Prof ${ }^{2,5,11}$, Giuseppe Pantaleo, Prof ${ }^{6,7}$, Felipe García, Prof ${ }^{8,9}$, Stefano Vella, Prof ${ }^{10}$, Yves Lévy, Prof ${ }^{2,5,11}$, Rodolphe Thiébaut, Prof ${ }^{2,3,4}$, Sheena McCormack, Prof ${ }^{1}$

\section{Affiliations:}

${ }^{1}$ MRC CTU, Institute of Clinical Trials and Methodology, University College London, London, United Kingdom;

${ }^{2}$ Vaccine Research Institute, Créteil, France;

${ }^{3}$ Univ. Bordeaux, Inserm, Bordeaux Population Health Research Center, team SISTM, UMR 1219, and Inria, F-33000 Bordeaux, France;

${ }^{4}$ EUCLID/F-CRIN clinical trials platform, CIC 1401, Univ. Bordeaux, Inserm, CHU Bordeaux, F-33000 Bordeaux, France

${ }^{5}$ INSERM U955, Paris Est Créteil University, Créteil, France;

${ }^{6}$ Service of Immunology and Allergy, Lausanne University Hospital, University of Lausanne, Lausanne, Switzerland;

${ }^{7}$ Swiss Vaccine Research Institute, Lausanne University Hospital, University of Lausanne, Lausanne, Switzerland;

${ }^{8}$ Infectious Diseases Department, Hospital Clinic of Barcelona - HIVACAT, University of Barcelona, Barcelona, Spain;

${ }^{9}$ Retrovirology and Viral Immunopathology Laboratory, AIDS Research Group, August Pi i Sunyer Biomedical Research Institute (IDIBAPS) - HIVACAT, Barcelona, Spain;

${ }^{10}$ Center for Global Health, Istituto Superiore di Sanità, Rome, Italy;

${ }^{11}$ AP-HP, Hôpital Henri-Mondor Albert-Chenevier, Service d'Immunologie clinique et maladies infectieuses, Créteil, France.

\section{Corresponding Author and Details:}

Cecilia L. Moore, PhD

MRC Clinical Trials Unit at UCL

Institute of Clinical Trials \& Methodology

90 High Holborn, London WC1V 6LJ

Direct line: +44 (0)20 7670-4902

e-mail: c.moore@ucl.ac.uk

Word Count: 3518 excluding references (Abstract 190) 


\begin{abstract}
The evaluation of immune-based approaches to achieve an antiretroviral therapy (ART)-free remission of HIV infection requires demonstration of efficacy through ART interruption placebo-controlled trials. This is not without risk to participants and there is a need to develop innovative trial designs which minimise the number of participants exposed to placebo and unviable candidates. Multi-arm multistage (MAMS) trial designs can be used in this context to accelerate the development of an immunebased therapeutic agent for HIV cure. Issues related to implementing a MAMS design within the EHVA T01 trial are considered here. EHVA T01 is a multicentre, MAMS, double-blind, phase I/II trial which aims to evaluate the impact of the immune interventions on viral control in HIV-1 infected participants following analytic treatment interruption (ATI). The application of a MAMS design increases the likelihood the EHVA T01 trial will identify a successful treatment and minimises the number of participants undergoing ATIs who have been exposed to futile agents. The use of MAMS is a promising design strategy to evaluate complex immune-based approaches aimed at curing HIV-infection, particularly relevant to the current pipeline with multiple agents requiring examination.
\end{abstract}




\section{Introduction}

The ideal therapeutic HIV immune-based intervention would eliminate the need for life-long antiretroviral therapy (ART) in HIV-infected individuals, either through eradication of all HIV-infected cells or by inducing an immune response capable of controlling the virus in the absence of ART (1-4). Over the last two decades, more than four dozen therapeutic immune-based approaches have been examined in clinical trials, most without any success in terms of their ability to control viral replication or maintain high CD4 counts in the absence of ART (reviewed in $(3,5-7)$ ). A few trials have produced more encouraging results (8-10) and there are currently a number of new immune intervention agents (vaccines and monoclonal antibodies) under development which require evaluation (11).

The current gold standard is to evaluate the efficacy of a new immune-based therapeutic intervention in a placebo-controlled superiority design where efficacy is determined via a short-term interruption of ART, also known as analytic treatment interruption (ATI), while monitoring for viral rebound $(3,12)$. While ATIs are considered clinically safe when closely monitored $(13,14)$, there are associated risks including acute retroviral syndrome, thrombocytopenia (15-17) and HIV transmission to others (1820) Within this context and in light of the number candidates currently requiring evaluation, there is a need to implement innovative trial designs which can optimise available resources to accelerate the evaluation of candidates while minimising the number of participants exposed to placebo or to unviable treatments. Adaptive trial designs such as the multi-arm, multi-stage (MAMS) trial design described by Royston, Parmar and Qian (21) could be used in this context to accelerate the development of a therapeutic HIV immune intervention agent.

The main features of MAMS trials are their ability to a) simultaneously compare multiple experimental arms against a common control thereby reducing the overall number of participants required in comparison to multiple parallel arm trials and $b$ ) allow for poorly performing arms to be dropped and new arms to be added at pre-specified interim analysis stages while controlling the overall risk of false positive conclusions (21-24). In contrast to adaptive designs which take only the most efficacious arms forward (e.g. 'pick-the-winner' type designs); the MAMS design is based on discontinuing the worst performing arms at each interim analysis. Because the decision to continue recruitment in an arm is based on lack-of-benefit as opposed to evidence-of-benefit, complicated bias adjustments for the inflation of the type I error rate are not necessary. Early looks at data within the MAMS design are made possible by taking a relaxed significance level at the interim stage while maintaining high power to ensure against incorrectly discarding an effective treatment early. MAMS trials have been successfully employed in a number of other disease areas, including tuberculosis and oncology research (25-27), and have been shown to require fewer participants and to be completed in a shorter time frame without loss of statistical validity or scientific integrity $(21,28)$ compared to standard designs.

There have been calls for adaptive designs to be more readily used in the evaluation of HIV-1 vaccines $(29,30)$ and they have been employed in a handful of prophylactic HIV vaccine trials (29-32), however to-date an adaptive design has not been used in the evaluation of therapeutic HIV agents. A number of methodological and practical considerations are needed in order to adapt the MAMS design to 
evaluate immune-based therapeutic interventions for HIV cure. These considerations are described herein and were motivated by the design of the EHVA T01 trial.

\section{EHVA T01 Trial Design}

EHVA T01 is an international, multicentre, MAMS, double-blind, Phase $\mathrm{I} / \mathrm{Il}$ trial that aims to evaluate three active interventions: 1 ) the combination of HIV vaccines, GTU-Multi-HIV B-clade DNA and ANRS MVA HIV-B (DNA+MVA arm), 2) a monoclonal antibody, vedolizumab (mAb arm), and 3) both the DNA+MVA with mAb (combination arm) against a placebo control arm in HIV-1 infected and virally suppressed adults recruited across 6 European collaborating countries (NCT02972450). The randomisation processes are detailed in Figure 1a. Participants will be randomised 1:1:1:1 to either DNA+MVA, mAb, combination or placebo stratified by stage of infection (chronic or primary infection). Participants in the placebo arm will be randomly assigned to receive a placebo for DNA+MVA, mAb or combination thereby ensuring blinding of placebo/intervention but not the schedule. In consideration of the higher burden associated with the greater number of treatment administrations in the combination arm schedule, it was decided that the schedule would be open-label.

The primary aim of the study is to assess the impact of the interventions on viral control following a treatment interruption (Figure 1b) with the hypothesis that active interventions are superior to placebo. Participants will continue on ART during the first 24 weeks covering the vaccination period and 5 of the $6 \mathrm{mAb}$ infusions (or matched placebo controls). The antiretroviral treatment will then be interrupted and resumed at the first occurrence of: i) a viral load confirmed to have rebounded to $\geq 10,000$ copies $/ \mathrm{ml}$, ii) a CD4 confirmed to have fallen to $\leq 350$ cells $/ \mathrm{mm}^{3}$, iii) symptomatic HIV progression or an AIDS defining conditions or iv) completion of 24 weeks of treatment interruption.

The trial is designed as a two-stage approach, an interim and a final efficacy stage. The primary outcome measure, which is assessed at both the interim and final efficacy stages, is time from treatment interruption (scheduled for 24 weeks after entering the trial) to the earliest time of reaching HIV RNA $\geq 10,000$ copies/ml (confirmed on a separate sample) or resuming antiretroviral therapy for any reason over a period of 24 weeks (herein referred to as viral rebound for ease). In light of previous therapeutic vaccine trials and the effectiveness of cART at suppressing viral replication, a $50 \%$ reduction in time to occurrence of viral rebound during ATI in each experimental arm compared to placebo was considered to be clinically relevant and the trial is powered to detect this at both stages.

\section{Interim Efficacy Stage}

The MAMS design with a time-to-event endpoint has a triggered analysis i.e. the interim analysis occurring when a set number of events have occurred within the control arm. For EHVA T01, the interim efficacy stage analysis will be performed after 11 events have been observed in the placebo arm i.e. when 11 participants receiving placebo have virally rebounded after the interruption of therapy, which is estimated to occur at around 50-52 weeks after the start of recruitment and in 14 participants who are receiving placebo (based on unpublished data from the VRI 02 ANRS 149 LIGHT trial (NCT01492985). The required number of events to trigger the interim analysis is determined via a number of factors including the randomisation ratio, the targeted treatment effect, the power and significance level targeted at the interim stage. More stringent levels in these factors e.g. lower 
significance level, higher power, a smaller targeted treatment effect, a lower expected failure rate will result in a greater number of events required at the interim stage.

The recruitment rate and the expected failure rate in the control arm impacts the length of time taken to accrue the number of events required to trigger the interim review but not the total number of events required. Fortunately, from a design perspective, in participants receiving placebo the expected failure rate in therapeutic vaccine trials is well known, as patients are expected to rapidly rebound once off therapy. The recruitment rate in any trial is somewhat difficult to predict and could impact the length of the trial with negative consequences regardless of whether the trial is designed as a MAMS or traditional randomised control trial.

In EHVA T01, individuals do not become at risk for the primary endpoint until 24 weeks after enrolment, when ART is interrupted. To ensure not too great a number of participants are enrolled prior to sufficient numbers of events occurring in placebo thereby triggering the interim analysis, it was decided to incorporate a pause in enrolment. Eighty-eight participants (22 participants per arm) will be recruited initially, at which point recruitment will be suspended until after the Independent Data Monitoring Committee (IDMC) reviews the interim stage data. Eighty-eight participants is higher than the required number of participants for the interim analysis but is considered an adequate minimum number for the evaluation of biomarkers of immunological response, a key secondary objective of the trial. We anticipate that the recruitment suspension between the enrolment of the $88^{\text {th }}$ participant and the occurrence of the interim analysis will last approximately 20 weeks and will require careful trial management and an efficient completion of the interim review in order to resume recruitment before centres lose momentum.

An early look at data is made possible by taking a relaxed significance level while maintaining high power to ensure against incorrectly discarding an effective treatment early (in EHVA T01 the interim analysis has a one-sided pairwise significance level of 0.500 and power of $95 \%$ ). At the interim review, as a guideline, the null hypothesis (no activity of the active intervention compared to placebo) can be rejected if the point estimate for the hazard ratio (HR) for an experimental arm is 1.00 or lower. In this case, the IDMC may recommend recruitment to the experimental arm continue to the final efficacy stage. If in contrast a HR>1.00 is observed, the IDMC may recommend, and the Trial Steering Committee (TSC) may subsequently decide, to discontinue recruitment to an experimental arm. However this is a non-binding guideline only and will need to be considered by the IDMC in the context of any other relevant internal and external data.

\section{Final Efficacy Stage}

If an arm passes the interim efficacy stage review, recruitment to that arm will subsequently reopen following the interim review. The total number of participants randomised to each arm and the duration of the trial will therefore depend on the number of arms successfully completing the interim stage. A stricter significance level is taken for the final efficacy analysis while still maintaining high power to limit the risk of false positive conclusions at the final stage. The final stage in EHVA T01 has a one-side significance level of 0.025 and a power of $92 \%$ for comparisons against the control arm. If all arms pass the interim stage, the total required sample size is estimated at 192 participants. The sample size calculations were performed using the STATA nstage program (version 3.0.1, 10-Sept2014). Table 1 outlines a number of key design parameters for a MAMS trial and considerations. 


\section{Efficiencies of the MAMS design and Comparisons with Other Design Options}

The multi-arm aspect of the MAMS design allows for several treatment arms to be tested concurrently, meaning multiple randomised comparisons are effectively being conducted under the same protocol. This is an efficient use of participants allocated to the control arm because fewer individuals are in the single control arm than if each additional therapy were tested against a control in separate two-arm trials. This is of particular importance when examining therapeutic HIV immune intervention agents where we want to minimise the number of individuals exposed to placebo undergoing ATIs.

Because one of the experimental arms in EHVA T01 is a combination of agents, a factorial design was also considered. However, it was not possible to rule out that the treatment strategies in the combination arm would have a synergistic effect; a core assumption for the accurate estimate of the main treatment effects in factorial designs. The presence of an interaction between treatments is often unable to be excluded in the context of immune interventions for HIV cure where the mechanisms of action are usually very much unknown and thus the use of factorial designs inappropriate.

With restricted resources, the traditional approach of conducting multiple phase 2 parallel-group randomized controlled trials for every potential new combination of agents before moving to phase 3 is a critical bottleneck for development of an immune-based therapeutic cure. The MAMS design is particularly applicable in this setting with little historical evidence of benefit for immune-based cure and several products requiring evaluation as it is an efficient method for selecting the most promising combinations. Figure 2 describes in more detail the savings and additional costs depending on different outcome scenarios resulting from the interim IDMC review (assuming that the IDMC fully follows the futility guidelines). If all experimental arms are shown to be futile, in EHVA TO1 the estimated savings were approximately 43 weeks off the length of the trial and 102 participants compared to a standard 4-arm trial with no interim analysis. If 1-2 experimental arms are shown to be futile, the savings in terms of the number of participants required is still significant albeit at some cost to the duration of the trial. If no arms are stopped for futility at the interim review then suspending recruitment to allow for the review of interim data will add 23 weeks to the overall duration of the trial compared to a standard 4-arm trial.

\section{The Role of MAMS Design in HIV Cure Research}

The applicability of the MAMS design to other types of HIV therapeutic cure trials depends on a number of practical considerations which should be weighed against the benefits before implementation. Generally in MAMS trials it is optimal to have a primary study outcome which is observed relatively quickly following randomisation so that interim analyses can occur soon after recruitment of the required sample size. If this is not possible then an intermediate outcome measure can also be used for the interim analyses as a means of screening for emerging evidence of activity. The use of an intermediate outcome of progression- or failure-free survival and primary outcome of overall survival is typically used in oncology MAMS trials. HIV cure trials vary from trial to trial in their assessment of primary study measures. In addition to time to rebound used in EHVA T01, measures in the past have included binary outcomes such as proportion of participants below a viral load threshold 
or proportion remaining off ART at a set time point during ATI, mean viral load set point, change in size of the viral reservoir and change in immunogenicity measures. All of these measures are able to be assessed quite rapidly, when compared to measures used in MAMS cancer trials, which is a strength as an intermediate outcome is not required.

A MAMS design requires timely data collection, as well as efficient analysis and decision-making processes, and may not work well in situations when the trial cannot be stopped promptly. Delays in assessment of the primary outcome measure, for example the requirement to transport samples to central laboratories for laborious assays, could reduce the benefit of an adaptive design as more participants would be randomised to arms ultimately determined to be futile or a required length of recruitment suspension would be too great. MAMS trials will likely also require the co-option of an independent data review committee who have additional expertise compared to a traditional data monitoring committee. Experience of adaptive trials in the independent data monitoring committee, for example, could be advantageous to ensure the scientific integrity of the decision-making process. Care must also be taken in blinded MAMS trials, such as EHVA T01, to ensure that cumulative events remain confidential to all blinded parties so that the occurrence of the interim review (and the known set number of events to trigger the interim review) does not comprise the blind.

MAMS and other adaptive clinical trial design have been available for more than 25 years and despite clear benefits in certain circumstances they are far from established in practice. This is likely due in part to the view that MAMS trials have complexities above that of a traditional randomized control trial. While practicalities of implementing a MAMS design in HIV cure research need to be carefully planned for, the greater flexibility offered within the MAMS design framework has the potential to translate into more ethical treatment of patients within HIV cure trials (possibly including the use of fewer patients), more efficient drug development, and better focusing of available resources. MAMS trials are particularly advantageous when there are multiple products to test, and in early-phase trials where there are more uncertainties, and thus more opportunity for considering adaptation.

\section{Discussion}

An adaptive clinical trial design approach was taken in the EHVA T01 trial to accommodate a need for flexibility in a context where participants should have limited risks of exposure to ATI when receiving an ineffective candidate treatment. By testing multiple experimental arms within one design, it increases the likelihood the trial will identify a successful treatment and it decreases the likelihood that the whole trial will be stopped prematurely, as it is unlikely that all candidates will be ineffective. By having an interim stage where recruitment into arms can be stopped for demonstrated futility, it also allows for resources to be saved and other potential therapeutic agents to be examined more speedily. The application of the MAMS design in this setting will, however, need to be considered in light of the likely need to suspend recruitment while the interim analysis occurs and the impact this will have on the length of a trial.

Adaptive trial designs are attractive and becoming increasingly popular in an effort to accelerate clinical development (32). The use of MAMS is a promising design strategy to evaluate complex therapeutic strategies aimed at curing HIV infection, particularly where there are multiple agents or combinations of agents to be examined and where short-term endpoints, such as viral rebound during ATIs, are to be used in the evaluation of treatment success. The application of MAMS in this setting is 
achievable, with some design considerations, and has the potential to reduce the number of participants exposed to unviable treatments and unnecessary treatment interruptions. However, statistical guidance and scenario planning is essential in order to develop a realistic adaptive trial framework with tangible savings.

\section{Contributors}

$\mathrm{CM}, \mathrm{SMc}$, WS conceived and drafted the manuscript. AMC, LR, J-DL, GP, FG, SB, YL, and RT made crucial revisions to and approved the final manuscript.

\section{Declaration of Interests}

J-DL reports personal fees from Gilead and personal fees from ViiV Health Care, outside the submitted work. All other authors declare no competing interests.

\section{Acknowledgements}

EHVA T01 is supported by the European Union's Horizon 2020 Research and Innovation Programme [grant numbers 681032] and the Swiss Government [grant number 15.0337]. The trial is also cofunded by VRI/Inserm-ANRS and sponsored by Inserm-ANRS. CM, SMc, WS and AMC are supported by the Medical Research Council [grant number MC_UU_12023/23]. The funders had no direct role in the writing of the manuscript or decision to submit it for publication.

MRC CTU at UCL: Nafisah Atako, Elizabeth Brodnicki, Anna Herasimtschuk, Silvia Forcat, Denise Ward, Selin Yurdakul, Mary Rauchenberger; INSERM-ANRS: Mireille Centlivre, Veronique Rieux, Laure Bourdery, Bruno Spire, Christine Lacabaratz, Christiane Moog; IAVI Stichting Netherlands: Hester Kuipers; Erasmus: Rob Gruters, Casper Rokx; ISS/INMI: Andrea Antinori, Chiara Agrati;

CHUV: Matthias Cavassini, Deolinda Alves, Rosemary Hottinger, Fabio Candotti, Francesco Procopio; IDIBAPS: Florencia Etcheverry; Saint-Louis Hospital: Jean-Michel Molina; MONDOR: Jose Luis LopezZaragoza; UKE: Julian Schulze-zur-Wiesch, Olaf Degen, Johanna Eberhard, Veronika Schlicker, Sindy Bartel, Sandra Hertling; Imperial College/SSAT including IAVI: Jonathan Weber, Cherry Kingsley, Marta Boffito, Ana Milinkovic, Peter Hayes, Sarah Joseph; AMC: Peter Reiss; ULVI: Bill Paxton, Georgios Pollakis; HPI: Marcus Altfield; EATG: Giulio Maria Corbelli; Fit Biotech: Kalevi Reijonen; Independent Data Monitoring Committee : James Wason, Merlin Robb, Pierre Delobel, David Haerry; Independent Members of Trial Steering Committee: James Kublin, Andriano Lazzarin, Simon Collins, Juergen Rockstroh 


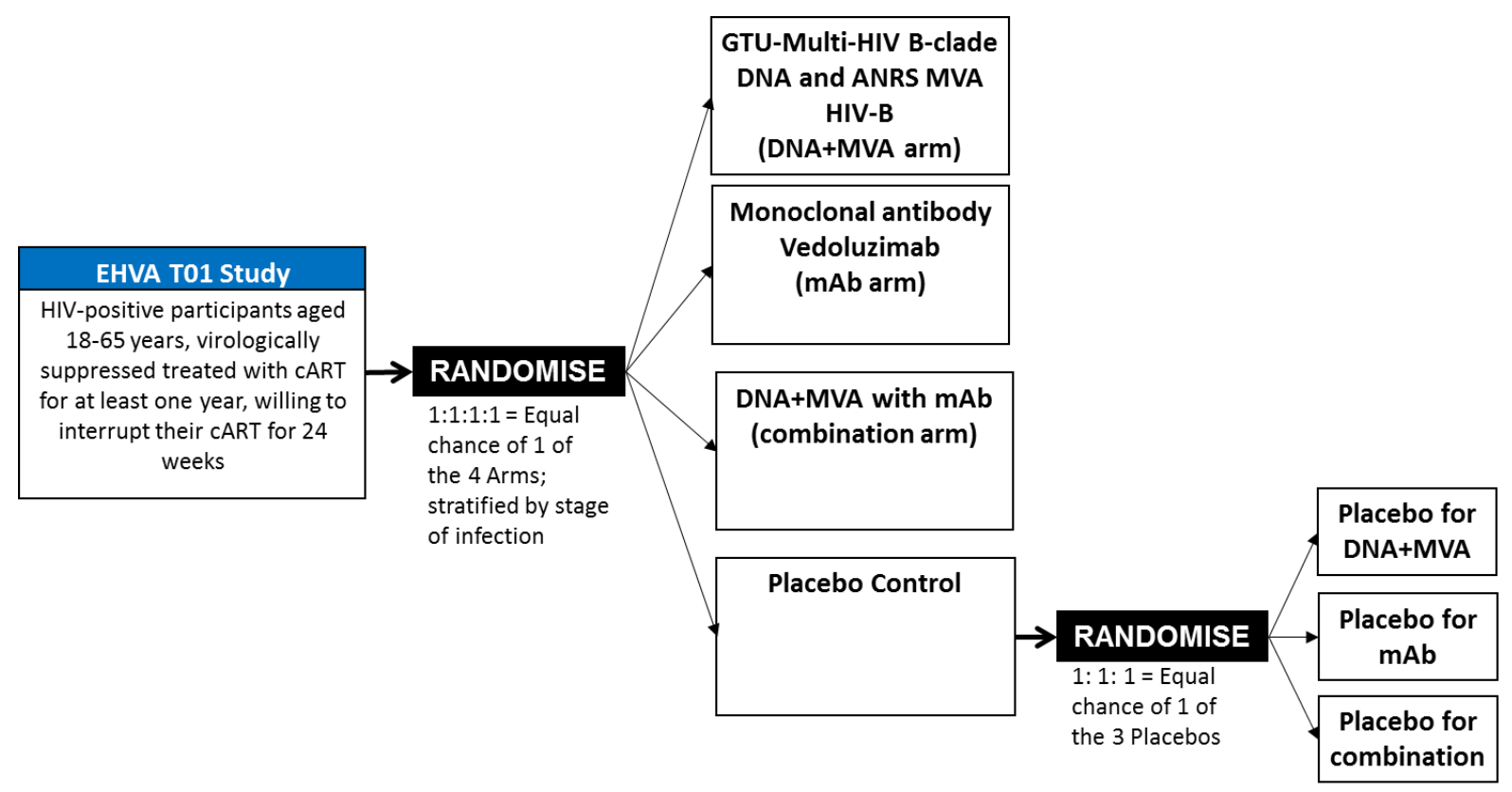

Figure 1a. EHVA T01 Randomisation Process.

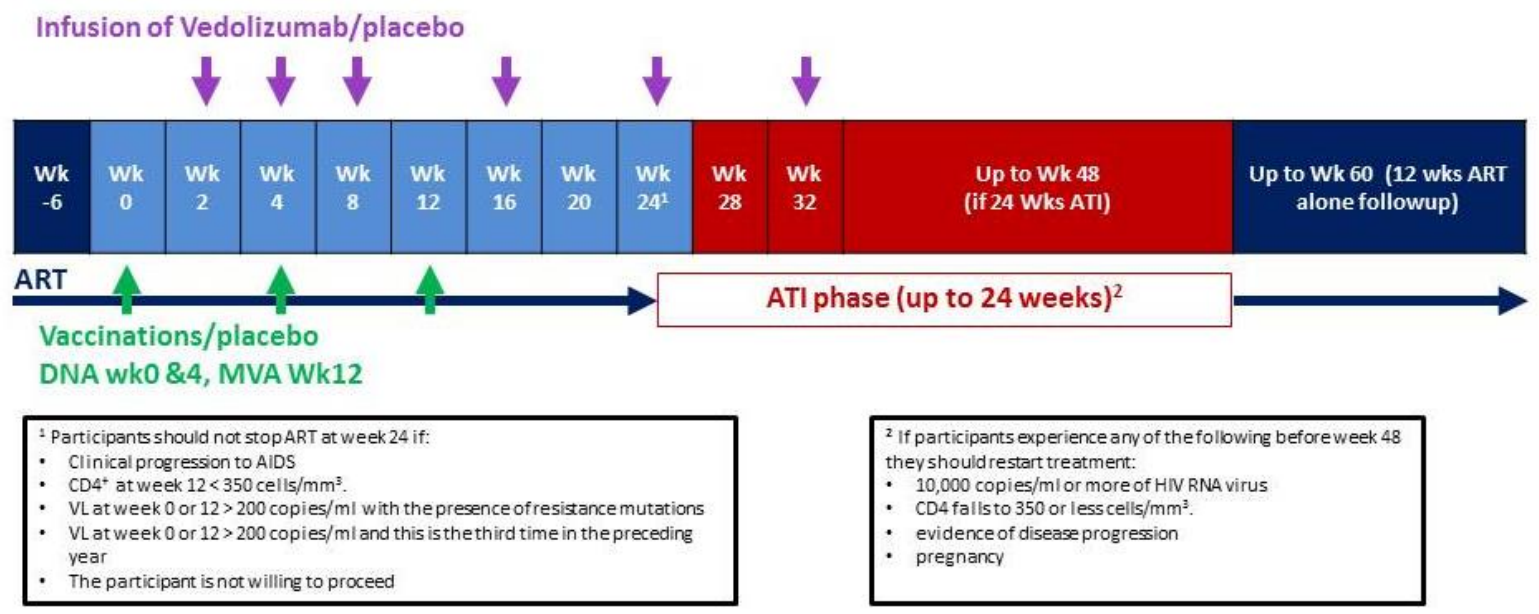

Figure 1b. EHVA T01 Trial Treatment Schedule. ATI=Analytic Treatment Interruption;

ART=Antiretroviral therapy 


\begin{tabular}{|c|c|c|c|c|}
\hline \multirow{5}{*}{$\begin{array}{l}\text { All arms } \\
\text { stopped for } \\
\text { futility }\end{array}$} & $\begin{array}{l}\text { Start of } \\
\text { Recruitment }\end{array}$ & $\begin{array}{l}\text { Interim } \\
\text { Analysis }\end{array}$ & $\begin{array}{l}\text { Restart } \\
\text { Recruitment }\end{array}$ & End of Recruitment $\rightarrow$ Final Analysis \\
\hline & PLACEBO & & & \multirow{4}{*}{$\begin{array}{l}\text { Saving } 102 \text { participants and } \\
\text { reducing length of trial by } \sim 43 \\
\text { weeks compared to a standard } \\
\text { 4-arm randomised control trial }\end{array}$} \\
\hline & EXPERIMENTAL & & & \\
\hline & EXPERIMENTAL & & & \\
\hline & EXPERIMENTAL & & & \\
\hline \multirow{4}{*}{$\begin{array}{l}\text { Two arms } \\
\text { stopped for } \\
\text { futility }\end{array}$} & PLACEBO & & & \multirow{4}{*}{$\begin{array}{c}\text { Saving } 50 \text { participants and } \\
\text { adding } 11 \text { weeks compared to a } \\
\text { standard } 4 \text {-arm randomised } \\
\text { control trial }\end{array}$} \\
\hline & EXPERIMENTAL & & & \\
\hline & EXPERIMENTAL & & & \\
\hline & EXPERIMENTAL & & & \\
\hline \multirow{4}{*}{$\begin{array}{l}\text { One arm } \\
\text { stopped for } \\
\text { futility }\end{array}$} & PLACEBO & & & \multirow{4}{*}{$\begin{array}{c}\text { Saving } 25 \text { participants and } \\
\text { adding } 17 \text { weeks compared to a } \\
\text { standard } 4 \text {-arm randomised } \\
\text { control trial }\end{array}$} \\
\hline & EXPERIMENTAL & & & \\
\hline & EXPERIMENTAL & & & \\
\hline & EXPERIMENTAL & & & \\
\hline \multirow{5}{*}{$\begin{array}{l}\text { No arms } \\
\text { stopped for } \\
\text { futility }\end{array}$} & PLACEBO & & & \multirow{5}{*}{$\begin{array}{c}\text { Requiring an additional } 2 \\
\text { participants and adding } 23 \\
\text { weeks compared to a standard } \\
\text { 4-arm randomised control trial }\end{array}$} \\
\hline & EXPERIMENTAL & & & \\
\hline & EXPERIMENTAL & & & \\
\hline & & & & \\
\hline & EXPERIMENTAL & & & \\
\hline
\end{tabular}

Figure 2. Possible MAMS scenarios at interim analysis and comparison with standard 4-arm trial in EHVA T01 
Table 1. Design parameters in EHVA T01 and considerations in defining parameters

\begin{tabular}{|c|c|c|}
\hline $\begin{array}{l}\text { Design } \\
\text { Parameter }\end{array}$ & $\begin{array}{c}\text { Final Analysis in } \\
\text { EHVA T01 }\end{array}$ & Considerations \\
\hline $\begin{array}{l}\text { Primary } \\
\text { outcome } \\
\text { assessed at } \\
\text { each stage }\end{array}$ & $\begin{array}{l}\text { Time from treatment interruption to } \\
\text { the earliest of reaching HIV RNA } \geq \\
10,000 \text { copies/ml or resuming } \\
\text { antiretroviral therapy for any reason }\end{array}$ & $\begin{array}{l}\text { The MAMS design is optimised where an intermediate outcome measure } \\
\text { is available which occurs earlier and more frequently than the final } \\
\text { outcome measure. The current gold standard in HIV therapeutic vaccine } \\
\text { trials is to evaluate the efficacy of a new candidate via viral rebound during } \\
\text { analytic treatment interruption }(3,11) \text {. Unfortunately until an immune } \\
\text { correlate of viral control sufficiently accepted to inform trial design is } \\
\text { identified, MAMS trials in the field will require both an intermediate and } \\
\text { final outcome which is definitive. }\end{array}$ \\
\hline $\begin{array}{l}\text { Distribution of } \\
\text { time to viral } \\
\text { rebound } \\
\text { during ATI in } \\
\text { the control } \\
\text { group }\end{array}$ & $\begin{array}{l}72 \% \text { of participant in the control arm } \\
\text { are expected to have virally rebounded } \\
\text { by week } 6 \text { following analytic treatment } \\
\text { interruption }\end{array}$ & $\begin{array}{l}\text { The distribution and the parameters of event occurrence in participants on } \\
\text { the control arm must be determined from previous study data. The } \\
\text { proportion of participants receiving placebo expected to virally rebound } \\
\text { during analytic treatment interruption in the case of EHVA T01 was } \\
\text { estimated from a similar placebo controlled analytic treatment } \\
\text { interruption trial in HIV-positive adults (VRI } 02 \text { ANRS } 149 \text { LIGHT trial } \\
\text { (NCT01492985)). }\end{array}$ \\
\hline
\end{tabular}

Experience from this and other trials $(33,34)$ suggest that an exponential distribution in time to viral rebound following analytic treatment interruption is appropriate.

\begin{tabular}{|c|c|c|c|}
\hline $\begin{array}{l}\text { Stage-wise } \\
\text { level of } \\
\text { significancet }\end{array}$ & 0.500 & 0.025 & $\begin{array}{l}\text { At the interim analysis this is the probability of not dropping an ineffective } \\
\text { arm. It is recommended that this is set to } 0.5 \text { at the first interim (23). This } \\
\text { relaxed level means that an early look is possible and that only very inferior } \\
\text { regimens will be dropped. At the final stage the significance level is set } \\
\text { more conservatively (0.025) to ensure that we do not incorrectly conclude } \\
\text { efficacy in an ineffective regimen. }\end{array}$ \\
\hline $\begin{array}{l}\text { Stage-wise } \\
\text { power }\end{array}$ & $95 \%$ & $92 \%$ & $\begin{array}{l}\text { This is the probability that a truly effective arm will not be dropped at an } \\
\text { analysis stage. This is kept very high ( } 95 \%) \text { at the interim stage to minimise } \\
\text { the possibility of incorrectly discarding an effective treatment early. }\end{array}$ \\
\hline $\begin{array}{l}\text { Targeted } \\
\text { treatment } \\
\text { effect }\end{array}$ & $\begin{array}{c}\text { Hazard Ratio }= \\
0.46\end{array}$ & $\begin{array}{c}\text { Hazard Ratio }= \\
0.46\end{array}$ & $\begin{array}{l}\text { For time to viral rebound during analytic treatment interruption, the } \\
\text { measure used to establish a treatment effect will be the hazard ratio. Given } \\
\text { what is achievable from treatment with ART alone, it is sensible to look for } \\
\text { a large treatment effect, which will reduce the overall expected trial size. } \\
\text { At both stages, the trial is powered to detect a } 50 \% \text { reduction in occurrence } \\
\text { of viral rebound during analytic treatment interruption in each } \\
\text { experimental arm compared to placebo (this translates into a hazard ratio } \\
\text { of } 0.46 \text { ). }\end{array}$ \\
\hline $\begin{array}{l}\text { Targeted } \\
\text { recruitment } \\
\text { rate leading up } \\
\text { to analysis }\end{array}$ & $\begin{array}{l}1 \text { participant per } \\
\text { week for the first } \\
4 \text { weeks, } 2 \text { per } \\
\text { week for the next } \\
4 \text { weeks and then } \\
4 \text { per week for } \\
\text { the remainder }\end{array}$ & 4 per week & $\begin{array}{l}\text { In the case of EHVA TO1 the DNA+MVA and mAb had never previously been } \\
\text { given in combination and it was necessary to start at a slower initial } \\
\text { recruitment rate to closely monitor safety events. While a slower than } \\
\text { anticipated rate of accrual impacts the overall length of the trial and time } \\
\text { to interim analysis, the required suspension in recruitment time, however, } \\
\text { is unaffected. }\end{array}$ \\
\hline
\end{tabular}

†one-sided significance level for each experimental arm vs. control pairwise comparison 


\section{References}

1.Yves L. Preparation for antiretroviral interruption by boosting the immune system. Current opinion in HIV and AIDS. 2008;3(2):118-23.

2.Vanham G, Van Gulck E. Can immunotherapy be useful as a "functional cure" for infection with Human Immunodeficiency Virus-1? Retrovirology. 2012;9:72.

3.Graziani GM, Angel JB. Evaluating the efficacy of therapeutic HIV vaccines through analytical treatment interruptions. Journal of the International AIDS Society. 2015;18:20497.

4.Puls RL, Emery S. Therapeutic vaccination against HIV: current progress and future possibilities. Clinical science (London, England : 1979). 2006;110(1):59-71.

5.Leal L, Lucero C, Gatell JM, Gallart T, Plana M, Garcia F. New challenges in therapeutic vaccines against HIV infection. Expert review of vaccines. 2017;16(6):587-600.

6.Garcia F, Leon A, Gatell JM, Plana M, Gallart T. Therapeutic vaccines against HIV infection. Human vaccines \& immunotherapeutics. 2012;8(5):569-81.

7.Ensoli B, Cafaro A, Monini P, Marcotullio S, Ensoli F. Challenges in HIV Vaccine Research for Treatment and Prevention. Frontiers in Immunology. 2014;5:417.

8.Levy Y, Gahery-Segard H, Durier C, Lascaux AS, Goujard C, Meiffredy V, et al. Immunological and virological efficacy of a therapeutic immunization combined with interleukin-2 in chronically HIV-1 infected patients. AIDS (London, England). 2005;19(3):279-86.

9.García F, Climent N, Guardo AC, Gil C, León A, Autran B, et al. A Dendritic Cell-Based Vaccine Elicits T Cell Responses Associated with Control of HIV-1 Replication. Science Translational Medicine. 2013;5(166):166ra2-ra2.

10.Pollard RB, Rockstroh JK, Pantaleo G, Asmuth DM, Peters B, Lazzarin A, et al. Safety and efficacy of the peptide-based therapeutic vaccine for HIV-1, Vacc-4x: a phase 2 randomised, double-blind, placebo-controlled trial. The Lancet Infectious diseases. 2014;14(4):291-300.

11.Treatment Action Group. Research Toward a Cure Trials 2019 [updated February 19 2019, last accessed February 22 2019]. Available from: http://www.treatmentactiongroup.org/cure/trials.

12.Lederman MM, Penn-Nicholson A, Stone SF, Sieg SF, Rodriguez B. Monitoring clinical trials of therapeutic vaccines in HIV infection: role of treatment interruption. Current opinion in HIV and AIDS. 2007;2(1):56-61.

13.Li JZ, Smith DM, Mellors JW. The need for treatment interruption studies and biomarker identification in the search for an HIV cure. AIDS (London, England). 2015;29(12):1429-32.

14.Clarridge KE, Blazkova J, Einkauf K, Petrone M, Refsland EW, Justement JS, et al. Effect of analytical treatment interruption and reinitiation of antiretroviral therapy on HIV reservoirs and immunologic parameters in infected individuals. PLOS Pathogens. 2018;14(1):e1006792.

15.Colven R, Harrington RD, Spach DH, Cohen CJ, Hooton TM. Retroviral rebound syndrome after cessation of suppressive antiretroviral therapy in three patients with chronic HIV infection. Ann Intern Med. 2000;133(6):430-4. 
16.Kilby JM, Goepfert PA, Miller AP, Gnann JW, Jr., Sillers M, Saag MS, et al. Recurrence of the acute HIV syndrome after interruption of antiretroviral therapy in a patient with chronic HIV infection: A case report. Ann Intern Med. 2000;133(6):435-8.

17.Ananworanich J, Nittaya P, Reto N, Wichitra A, Ponlapat R, Sasiwimol U, et al. Recurring Thrombocytopenia Associated with Structured Treatment Interruption in Patients with Human Immunodeficiency Virus Infection. Clinical Infectious Diseases. 2003;37(5):723-5.

18.Gray RH, Wawer MJ, Brookmeyer R, Sewankambo NK, Serwadda D, Wabwire-Mangen F, et al. Probability of HIV-1 transmission per coital act in monogamous, heterosexual, HIV-1-discordant couples in Rakai, Uganda. The Lancet. 2001;357(9263):1149-53.

19.Quinn TC, Wawer MJ, Sewankambo N, Serwadda D, Li C, Wabwire-Mangen F, et al. Viral Load and Heterosexual Transmission of Human Immunodeficiency Virus Type 1. New England Journal of Medicine. 2000;342(13):921-9.

20.Lelievre JD, Hocqueloux L. Unintended HIV-1 Transmission to a Sex Partner in a Study of a Therapeutic Vaccine Candidate. The Journal of infectious diseases. 2019.[Epub ahead of print]

21.Royston P, Parmar MKB, Qian W. Novel designs for multi-arm clinical trials with survival outcomes with an application in ovarian cancer. Statistics in medicine. 2003;22(14):2239-56.

22.Bratton DJ, Phillips PP, Parmar MK. A multi-arm multi-stage clinical trial design for binary outcomes with application to tuberculosis. BMC Medical Research Methodology. 2013;13(1):139.

23.Royston P, Barthel FM-S, Parmar MK, Choodari-Oskooei B, Isham V. Designs for clinical trials with time-to-event outcomes based on stopping guidelines for lack of benefit. Trials. 2011;12(1):81.

24.Sydes MR, Parmar MK, James ND, Clarke NW, Dearnaley DP, Mason MD, et al. Issues in applying multi-arm multi-stage methodology to a clinical trial in prostate cancer: the MRC STAMPEDE trial. Trials. 2009;10(1):39.

25.Kaplan R, Maughan T, Crook A, Fisher D, Wilson R, Brown L, et al. Evaluating Many Treatments and Biomarkers in Oncology: A New Design. Journal of clinical oncology : official journal of the American Society of Clinical Oncology. 2013;31(36):4562-8.

26.Phillips PP, Gillespie SH, Boeree M, Heinrich N, Aarnoutse R, McHugh T, et al. Innovative trial designs are practical solutions for improving the treatment of tuberculosis. The Journal of infectious diseases. 2012;205 Suppl 2:S250-7.

27.Sydes MR, Parmar MK, James ND, Clarke NW, Dearnaley DP, Mason MD, et al. Issues in applying multi-arm multi-stage methodology to a clinical trial in prostate cancer: the MRC STAMPEDE trial. Trials. 2009;10:39.

28.Barthel FM, Parmar MK, Royston P. How do multi-stage, multi-arm trials compare to the traditional two-arm parallel group design--a reanalysis of 4 trials. Trials. 2009;10:21.

29.Corey L, Nabel GJ, Dieffenbach C, Gilbert P, Haynes BF, Johnston M, et al. HIV-1 vaccines and adaptive trial designs. Sci Transl Med. 2011;3(79):79ps13.

30.Moodie Z, Janes H, Huang Y. New Clinical Trial Designs for HIV Vaccine Evaluation. Current opinion in HIV and AIDS. 2013;8(5):10.1097/COH.0b013e328363d46a. 
31.Gilbert PB, Grove D, Gabriel E, Huang Y, Gray G, Hammer SM, et al. A Sequential Phase 2b Trial Design for Evaluating Vaccine Efficacy and Immune Correlates for Multiple HIV Vaccine Regimens. Statistical communications in infectious diseases. 2011;3(1).

32.Richert L, Doussau A, Lelievre JD, Arnold V, Rieux V, Bouakane A, et al. Accelerating clinical development of HIV vaccine strategies: methodological challenges and considerations in constructing an optimised multi-arm phase I/II trial design. Trials. 2014;15:68.

33.Angel JB, Routy JP, Tremblay C, Ayers D, Woods R, Singer J, et al. A randomized controlled trial of HIV therapeutic vaccination using ALVAC with or without Remune. AIDS (London, England). 2011;25(6):731-9.

34.Treasure GC, Aga E, Bosch RJ, Mellors JW, Kuritzkes DR, Para M, et al. Brief Report: Relationship Among Viral Load Outcomes in HIV Treatment Interruption Trials. Journal of acquired immune deficiency syndromes (1999). 2016;72(3):310-3. 